\title{
Inferentialism, Context-Shifting and Background Assumptions
}

\section{Bartosz Kaluziński ${ }^{1}$ (1)}

Received: 21 March 2020 / Accepted: 19 October 2020 / Published online: 23 November 2020

(c) The Author(s) 2020

\begin{abstract}
In this paper I present how the normative inferentialist can make the distinction between sentence meaning and content of the utterance. The inferentialist can understand sentence meaning as a role conferred to that sentence by the rules governing inferential transitions and content of the utterance as just a part of sentence meaning. I attempt to show how such a framework can account for prominent scenarios presented by contextualists as a challenge to semantic minimalism/literalism. I argue that inferentialism can address contextualist challenges in a simple and effective manner by understanding sentence meaning as broad, but invariant.
\end{abstract}

\section{Introduction}

In the recent years one can observe growing interest in the issue of contextualism in the philosophy of language; this is the view that emphasizes the role that extralinguistic context plays in determining linguistic meaning (e.g. Recanati 2004, 2010; Travis 1997; Borg 2004, 2012; Cappelen and Lepore 2005; Stanley 2007). Traditionally, following Grice (1957), it is claimed that one should distinguish between context-invariant sentence meaning (that is a domain of semantics) and contextsensitive content of utterance (which may be heavily influenced by pragmatics). It seems pretty obvious that certain expressions are context-sensitive, for example "I" or "foreign". The expression "I was the 44. President of the US" expresses a different proposition when the utterer changes. Its truth-value is also affected by context: it is true when uttered by Barack Obama, and false when uttered by anybody else. The "I" in this utterance refers to the person who actually is uttering it. Similarly, the content of "This is a foreign car" is heavily influenced by an extralinguistic factor, namely the place where it is uttered. For example, it would be true of VW

Bartosz Kaluziński

bartosz.kaluzinski@amu.edu.pl

1 Faculty of Philosophy, Adam Mickiewicz University in Poznań, Szamarzewskiego Street 89c, 60-568 Poznań, Poland 
Golf when uttered in Paris, but it would be false when uttered about the same car in Berlin.

The advocates of contextualism claim that there are much more context-dependent expressions than these obvious examples presented above. To support their claim, they use different types of arguments:

I. they claim that when the extralinguistic context is shifting, there is a change in meaning;

II. they claim that semantically determined truth-conditions are unintuitive and play no role in ordinary communication;

III. they claim that semantics is unable to determine the meaning of the sentence and there is a need for involvement of certain pragmatic processes and/or background assumptions.

In this paper I investigate more closely several scenarios presented by contextualists as a challenge for semantic minimalism. These have been the subject of an intense debate but I would like to tackle them from a little unorthodox perspective, namely normative inferentialism.

In the following sections I outline main positions in the debate concerning context-dependence of linguistic expressions. Next, I present what an inferentialist approach to linguistic meaning consists of and how inferentialist can distinguish sentence-meaning and content of utterance. Finally, I outline how it is possible to deal with several common contextualist arguments from an inferentialist perspective.

\section{Literalism/Minimalism Versus Contextualism}

It is very hard to present the main positions in the debate concerning contextdependence of linguistic expressions in an uncontroversial way because these positions are not homogeneous and the debate is very much ongoing. So, I attempt to present these positions in a very generic way. It is often said that the debate concerning contextualism is a debate concerning specification of the domains of semantics and pragmatics: we attempt to draw a boundary between semantics (concerned with meanings of sentences) and pragmatics (concerned with the use a speaker makes with sentences). Roughly speaking, literalists and minimalists claim that semantics is basically autonomous, while contextualists emphasize the ubiquity of pragmatic influence on Gricean "what is said". Now, let me very briefly sketch three main currents in the debate:

- Literalism, which is the most classical view, can be found in Kaplan (1989). In terms of quantity, literalism claims that there are very few context-sensitive expressions, like the following: I, you, she, this, that, present, local, foreigner, here, now, today, enemy, native. Extension of these expressions changes from context to context, but what is important is that it is affected by a limited number of parameters; according to Lewis (1970), there are four of them: agent, time, 
place, possible world (however, it is usually assumed that there can be more parameters). Roughly speaking, expressions like "I", "today" or "native" are associated with rules determining the content of the expression (given a context of utterance). Kaplan calls these rules characters. The character of "today" is a function from context to content: in a context in which it is uttered on 14th July, it delivers a content which determines 14th July as reference; in a context in which it is uttered on 24th December, it delivers a content which determines 24th of December as reference, etc.

- Minimalism (Borg 2004, 2012; Bach 1994, 2001; Cappelen and Lepore 2005) is a view that builds on literalism and agrees with literalism that there are few expressions that are context-dependent. Minimalists claim that semantic theory consists of lexicon, syntax and minimal pragmatic intrusion; the only pragmatic influences that are accepted are those that are absolutely necessary to determine sentence's truth-conditions. One can find an influential example of minimalism in Cappelen and Lepore (2005). They claim that the traditional distinction between semantics and pragmatics ("what is said" and "what is meant") should be maintained, perhaps with a few adjustments. Cappelen and Lepore (2005) call the semantic content of a sentence its "minimal content". What is "minimal content"? If one says, "It is raining", the semantic content of that utterance is the proposition that there is some place (anywhere in the whole universe) where there is an episode of raining at the time when the sentence is uttered. One can say that the "minimal content" of the sentence "It is raining" is what is common to all utterances of that sentence. Cappelen and Lepore claim that the minimal content is "static" and invariant, but there is a plurality of speech acts contents, and the minimal content of a sentence is always one of many contents that its utterances express.

- Contextualism is not homogeneous theory, and it can have a more radical (Searle 1978, 1992; Travis 1997) or modest form (Recanati 2004, 2010; Sperber and Wilson 1986; Carston 2002). However, what seems common to many contextualists is the thesis that context-dependent expressions are omnipresent, and we should get rid of the traditionally understood semantic "what is said" because it is enormously influenced by multiple pragmatic processes (like free enrichment, transfer and loosening). There are numberless background assumptions that can contribute to the sentence meaning, and the meaning of virtually any given expression changes when the context of the utterance changes. Contextualists deny that there is such a thing as "minimal content" or, at best, it is some very abstract entity that is completely useless in explaining everyday communication.

\section{What is Inferentialism?}

In the philosophy of language the dominant view concerning linguistic meaning might be called representationalism. It claims, quite intuitively, that meanings of linguistic expressions are some abstract entities glued to these expressions by our minds. However, there are also alternative views, most notably a family of usetheories of meaning. One can say that the roots of use-theories of meaning can be 
attributed to Wittgenstein $(1967,1969)$. The first philosopher who explicitly placed the notion of inference at the centre of the theory of meaning, thus, a founder of specifically inferential theory of meaning, was Wilfrid Sellars (2007). ${ }^{1}$ More recently, theory of such a type was extensively elaborated by Brandom $(1994 ; 2000 ; 2007)$ and Peregrin $(2014 ; 2018)$. According to such theories, the meaning of the linguistic expression is its inferential role. Roughly speaking, to grasp the meaning of "father" is to be prepared to make linguistic moves of the following kind:

" $x$ is a father" $\rightarrow$ " $x$ is a male".

"x is a father" $\rightarrow$ "x has at least one child".

Inferential theories of meaning, which belong to the family of use-theories of meaning, can be understood in at least two basic ways. The approach that I am particularly interested in, might be called "normative inferentialism". It is a theory that claims that linguistic meaning is constituted by those material inferences (transitions, moves) one ought to or may (not) make. The grasp of meaning is, according to these theories, an ability to distinguish the properly made transitions from incorrect ones. According to normative inferentialism, the linguistic expression is its role in the practice of speaking language and that role is determined by a set of rules that tell us which inferential transitions are correct and which are not. One should be aware that inferentialism may not be understood in such a normative way. Most notably, Paul Boghossian (1993, 1994, 2003, 2012) considered the naturalistic version of inferentialism, quite frequently called Inferential Role Semantics. This type of theory assumes that meaning constituting inferences are not those that are correct, but those that speakers of a language normally or typically make (or are disposed to make).

Inferential theories have been quite popular in logic and philosophy of logic. There were numerous attempts to account for logical constants in terms of roles, as well as ardent criticisms of such attempts (cf. Prior 1960; Belnap 1962; Dummett 1973; Cozzo 1994; Felscher 2002; Peregrin 2006; Fouqueré and Quatrini 2013; Warren 2015; Francez 2015; Zangwill 2015). However, inferentialists do not need to restrict themselves to accounting of logical vocabulary, but they strive to provide a theory of meaning that includes also empirical vocabulary (Brandom 1994; Peregrin 2014). How do inferentialists try to do that? Inference is normally a move from one statement to another, so it seems to be somehow "detached" from empirical reality. To avoid such an unwelcome conclusion, inferentialists propose to broaden the notion of inference "so that we are able to talk about inferences from situations to utterances and from utterances to actions" (Peregrin 2014, p. 32).

Now, let me say a few words on how such broadening may look like in practice. Inferentialists like Peregrin or Brandom seem to follow Sellars on distinguishing three types of inferential "moves" or "transitions":

$\alpha$ from situations to sentences.

$\beta$ from sentences to sentences.

$\overline{1}$ However, one can find very similar ideas even earlier in Ajdukiewicz (1934) 


\section{$\gamma$ from sentences to actions. ${ }^{2}$}

Transitions of the type $\alpha$ are the ones that are determined by rules usually tying sentences with reality; for instance there is a rule within the linguistic community that tells us that we are allowed to say "This is a tiger" when pointing to a tiger. These inferences are crucial, but, according to Peregrin, not sufficient to establish language:

Can an empirical word become meaningful just by being 'tied to the world' in the above sense? ... Consider a cat emitting a peculiar kind of hiss when it sees a dog: the hiss, in the mouth of the cat, appears to be tied to the same situations to which the sentence This is a dog is in the mouth of a speaker of English. So why do we say that the latter is a meaningful sentence, a description of the situation, whereas the former is a mere reaction to the situation? The reasons usually stem from the fact that the human utterer ... deals with language with the versatility characteristic of thinking ... Her utterance is embedded within a richly structured spectrum of other utterances, hence we assume that the sentence is part of a certain network of other sentences (Peregrin 2014, pp. 29-30).

Since connecting certain sentences with relevant situations is insufficient to "establish" language competence, there is a need for $\beta$ type of inferences. These rules allow us to infer that if " $x$ is a tiger", then (i) " $x$ is an animal", (ii) "x is not a fish", (iii) " $x$ is a carnivore" etc. Finally, there are rules that tell us how to make $\gamma$ type of inferences, for example if " $x$ is a tiger", then (i) "one should keep distance from x", (ii) "one should not irritate $x$ " etc.

The meaning of a linguistic expression is, thus, determined by rules that tell us what inferences of the types $\alpha, \beta$ and $\gamma$, we may or should (not) make. ${ }^{3}$ The meaning of a sentence is considered by inferentialist as a role that that sentence plays in the practice of speaking the language. Such a role is analogous to the role tennis racquet plays in the practice of playing tennis matches or that a rook plays in the practice of chess matches. Context is much included in the determination of the role of an item in the game. The moves we are allowed, prescribed or forbidden to make are affected by situation on the playing ground (chessboard, boxing ring, tennis court etc.), for instance, the role a pawn play in the game of chess is conferred to a wooden piece by the following rules:

\footnotetext{
2 Note that Sellars used terms "Language Entry Transitions", "Intra-linguistic Moves" and "Language Exit Transitions". Sellars speaks that way because he is used to traditional, narrow notion of inference. Inferentialists such as Brandom and Peregrin broaden the notion of inference to such extent that it seems to be a metaphor, so they can speak of "inferences from situations to sentences" and "inferences from sentences to actions". In this paper, I use notion of inference, move and transition interchangeably.

3 Inferential theories of meaning are holistic. This feature of inferentialism is often criticised because allegedly, in order to know the meaning of certain expression $e$, we need to know all rules within a language expression $e$ belongs to. However, it seems that inferentialist is not necessarily committed to such problematic version of holism. One recent version of some modest alternative can be found in Warren (2015).
} 
(R1) a pawn can be moved one box forward.

(R2) if it is the pawn's first move, it can be moved two boxes forward.

(R3) a pawn can capture one of the opponent's pieces by moving diagonally forward one square to the left or right.

(R4) a pawn on its fifth rank may capture an enemy pawn on an adjacent file that has moved two squares in a single move, as if the pawn had moved only one square (en passant).

\section{Inferential Significance and Inferential Potential}

I have presented the general idea of how a normative inferentialist can understand sentence meaning; now it is time to investigate the issue of how he or she can account for the content of the utterance. The most prominent inferentialist, Robert Brandom, claims that "contents are essentially social and perspectival in nature (1994, p. 197)". However, one must admit that he does not provide us with a wellstipulated account of the relation between sentence meaning and utterance content; it is just a slogan we have in his papers. Fortunately, Matej Drobňák (2020) has recently presented how an inferentialist may understand that issue. He distinguishes between inferential potential and inferential significance. The former can be understood as basically equivalent to the role of a pawn as determined by the set of abovementioned rules (R1)-(R4): it is the whole spectrum of moves (inferences) one is allowed to make and it involves collateral premises (e.g. "a pawn on its fifth rank" or "enemy pawn on an adjacent file that has moved two squares"). The latter is a "part" of the whole role of a pawn, for instance (R4) en passant. Finally, one should distinguish a move the player makes according to the rules in certain circumstances; for instance, that a player makes an en passant capture, given his or her pawn is on its fifth rank and the enemy's pawn is on an adjacent file that has moved two squares; this is equivalent to specific utterance made by the speaker in certain context. As noted by Drobňák:

The process of contextual modulation is a process in which we delimit a specific part of meaning, or in which we specify a particular aspect of meaning. The content of an utterance is not an outcome of a change of meaning; it is an outcome of a specification/narrowing of meaning for a particular context. (2020, p. 43).

Inferentialists often appeal to the analogy between games and language. This should not be surprising, given that the founding father of all use-theories of meaning Ludwig Wittgenstein used to exercise this analogy a lot. However, the issue of inferential potential and inferential significance can be presented in a less metaphoric manner. ${ }^{4}$ To use Drobňák's example, the simplified inferential potential of the sentence "Fido is a dog" can be:

\footnotetext{
4 In this paper, I follow Drobňák's distinction between inferential potential and inferential significance. One should note that Peregrin (2014: chapter 3) presented that distinction slightly different.
} 
IP("Fido is a dog") =

(a) < "Fido barks", "Fido is a carnivore", ..., "Fido is a living being" $>1$ "Fido is an animal"

(b) < "Fido barks", "Fido is not a carnivore", "Fido is not a living being", ..., "Fido is made of metal and plastic"| "Fido is a robot" >

(c) < "Fido does not bark", "Fido is not a carnivore", "Fido is not a living being", ..., "Fido is made of plush" $>$ | "Fido is a plush toy"

So, the simplified inferential potential of the sentence "Fido is a dog" contains several inferential significances like the ones (a), (b) and (c). These inferential significances say what can be correctly inferred (marked by "I") from the sentence "Fido is a dog", given that certain collateral premises (which are marked by " $<,>$ ") are true. For example, the sentence "Fido is an animal" can be inferred from "Fido is a dog", taking into account the collateral premises "Fido barks", "Fido is a carnivore", "Fido is a living being", etc. "Fido is a robot" can be inferred from "Fido is a dog" and certain collateral premises like "Fido is made of metal and plastic". The content of an utterance (inferential significance) is just a subset, a part of sentence meaning (inferential potential). ${ }^{5}$

Let me make a few clarifying remarks. First, the presented inferential potential of the sentence "Fido is a dog" is simplified in two ways. The inferential potential of a sentence $s$ consists of two sets of sentences (or circumstances): (i) the ones that can be inferred from $s$, (ii) the ones that $s$ can be inferred from. In this example, for the sake of simplicity, I focus only on (i). The inferential potential is simplified also because it may not be complete; possibly there are more inferential significances of "Fido is a dog" than (a), (b) and (c).

Second, what was traditionally understood as the extralinguistic context of utterance is here understood as collateral premises (marked by " $<,>$ "). The meaning of the sentence "Fido is a dog" is determined by rules telling us what inference we are allowed to make from that sentence (and from what sentences or circumstances we are allowed to infer that "Fido is a dog"). Hence, the meaning of the sentence "Fido is a dog" is broad (one can also call it "heavy" or "rich"). We are allowed to infer from that sentence that "Fido is a robot" or "Fido is an animal", and context plays a critical role in such inferences: it simply tells us what inferences would be correct on any particular occasion. Once again, the situation seems very similar to the practice of playing chess. Imagine you are sitting at the chessboard and it is your turn. The pawn on the square a2 can be moved two squares forward. However, if that same pawn has been moved before, you are not allowed to move it two squares forward. So, the meaning of an utterance is analogous to the role a pawn plays in the practice of playing chess matches, and it consists of (possibly multiple) contents which are analogous to the rules concerning how one may move a pawn. Context is analogous to the situation on the

\footnotetext{
${ }^{5}$ One can find a slightly more technical formulation of the distinction between inferential potential and inferential significance in Drobňák (2020).
} 
chessboard: it narrows/specifies which move from the whole spectrum of possible moves we are allowed to make (which content the utterance has).

Third, one may worry that the set of collateral premises involves "...", so there are potentially numberless collateral premises that in effect will make all inferences correct. This is not true, however. The "..." is meant only to mark that there is some possibility that the collateral premises I have listed are not the only ones. What seems to be crucial is the fact that normative inferentialism is an essentially social theory, and meaning is determined by rules that are common within linguistic society. So, one cannot infer from "Fido is a dog" that "Fido is a robot", given that any collateral premise is true (e.g. "Dolphins are not birds", "Volkswagen is a German car" etc.), because there are absolutely no rules within the linguistic society that would allow us to do so.

In the debate concerning context dependence, it is discussed whether there is a sharp difference between context-invariant sentence meaning (which is the domain of semantics) and context-sensitive content of utterance (which is the domain of pragmatics). Although sentence meaning is normally understood in terms of truth-conditions, there seems to be no obvious obstacles to treat inferential potential as an inferentialist version of sentence meaning and inferential significance as an inferential version of content of utterance.

\section{How Can an Inferentialist Account for Contextualist Arguments?}

How might the general idea presented in the previous section work? The proof of the pudding is in the eating, so in the following paragraphs I analyse how one can respond to some of the examples provided by contextualists as very problematic for semantic minimalism. I will try to show how a normative inferentialist can account for them. There are multiple such scenarios. I have decided to select several of them that are concerned with empirical vocabulary (so I restrain myself from those examples presented by contextualists that are concerned with logical constants or quantifiers) and appear to be the very prominent, however there is some subjectivity with the selection process that is hard to avoid.

\section{A. Green leaves}

Consider the following scenario sketched by Charles Travis (1997). There are two people, say, John and Mary. John is an owner of a house with a big garden and in that garden there is a maple tree with brown leaves. Mary is a botanist working at the local university. John is convinced that leaves of all trees should be green, so he takes a green paint and uses it to change his maple tree leaves colour from brown to green. Mary asks John if he has any green leaves that she needs for conducting her research. John says "Take these leaves. They are green" (when pointing to the abovementioned maple), but botanist Mary seems to disagree: "These leaves are not green!". 
How can an inferentialist account for that situation? It appears that the starting point should be the sketch of the inferential potential of the sentence "This is green". The inferential potential of that sentence is a role within the network of inferences. Apparently, crucial rules are those that determine correctness of inferences tying the concept of greenness to the world. For instance:

(green) This is green (when pointing to fresh grass in normal lightning conditions).

Next, one can infer from "This is green" that "This has colour", "This is not red" etc. The sentence "This is green" can be correctly applied to things that are green "by their nature" (like fresh grass) or to things that have that colour because they were made by someone to look that way (for example, a car or a wall painted green). So, the inferential potential of the sentence "This is green" is broad enough to justify applying that sentence to both things green "by themselves" and "made green". There also might be the case that sometimes we do not distinguish between objects being naturally and artificially green. It appears that there may be some third inferential significance, let me label it "just green", when we say of green things that they are green, regardless of the greenness "origin". So, it appears that there are multiple inferential significances and one inferential potential of "This is green". In the abovementioned scenario, John's utterances have inferential significance "Made green" (or perhaps “Just green”), while Mary's utterance has inferential significance "Green by their nature". 6 There was no shift in sentence meaning since the inferential potential of "This is green" is broad enough to include "Green by their nature", "Just green" and "Made green". These sentences are parts of few different subsets of inferential potential of "This is green". These sentences have different inferential significances, given certain collateral premises are true (for instance, "someone painted that thing green" or "nobody changed that thing's natural colour"). There is a difference in content of the utterance: Mary means that the leaves are not green by their nature and John means that they are painted green (or just green). To sum up, the sentence "This is green" has one meaning and multiple contents.

\section{B. Red apple}

Consider another example: a speaker says "This apple is red" (cf. Bezuidenhout 2002). It would appear as though this sentence is clear. Obviously, that sentence is true if and only if the apple in question actually is red. But contextualists claim that without some background knowledge, we cannot determine what counts as being red for that apple. This is the case because the sentence "This apple is red" may be applied to the colour of that apple's skin or to the colour of its pulp that has changed because of, say, a specific fungus infection.

\footnotetext{
6 These are labels that I give to the parts of inferential potential. This is the same move that is made by labelling (R4) "en passant". I do that thorough the paper for the sake of simplicity: one can use a label instead of invoking the whole rule or set of rules.
} 
This case is very much alike A. scenario. Apparently, the correctness of inference from situation to sentence of the following type:

(red) "This is red" (when pointing at a typical double-decker bus in normal lightning conditions).

is absolutely crucial to determining the meaning of the sentence "This is red". The inferential potential of "This is red" seems to be broad enough to include multiple situations, among others: (1) when something is red on its surface and (2) when it is red on the inside. Intuitively, there is nothing weird about calling a watermelon red, even if its surface is green. So, there is one inferential potential of the sentence "This apple is red" that contains following inferential significances:

(1) "this apple has not been painted", "this apple has a skin", "the colour of the skin is the same as colour of typical double-decker bus" and from that set of premises we can infer that "this apple is red on its surface".

and

(2) "this apple has a pulp of the same colour as typical double-decker bus", "this apple is sick" etc. and from that set of premises we can infer that "this apple is red on the inside".

Note that these two inferential potentials differ with the inferences from sentences to actions that we are allowed to make. From "This apple is red", we can infer that (1) "this apple is ripe" and "this apple is edible" or (2) "one should avoid eating that". We have one inferential potential (sentence meaning) and two different inferential significances (utterances contents). Note that since John's and Mary's utterances have different content they are not inconsistent in the sense that they both can be true at the same time. Nevertheless, they would still differ in $\gamma$ type inferences: one should not eat that apple if it has a red pulp due to fungal infection.

\section{John is tall}

The sentence "John is tall", at the first glance, seems to be clear, but contextualists claim that we cannot determine its meaning and truth-value without the knowledge whether John we are talking about is, for example, a seven-year-old boy or a professional basketball player. There are very different standards of tallness for these two groups of people.

Perhaps I should start from noticing that "tall" is widely considered to be a vague term. So in order to avoid discussing two different topics at the same time, one should ignore the phenomenon of vagueness at this point. It seems to me that the inferential potential of the sentence " $S$ is tall" is partly determined by a certain feature of reality, which is a person's tallness, and certain collateral premises, for instance: 
(1) from "S is $220 \mathrm{~cm}$ ", and collateral premise "S is professional basketball player", we can infer that " $S$ is tall" (and from that sentence, we can infer, for instance that "S can slam-dunk").

(2) from "S is $140 \mathrm{~cm}$ ", and collateral premise "S is 7 year-old-boy", we can infer that " $\mathrm{S}$ is tall" (and from that sentence we can infer, for instance that "S can reach the book on that shelf").

The tallness ascriptions seem to be specific: we cannot make an inference from situation to sentence "directly", without any collateral premises. An inference from situation to sentence, without any "additional" collateral premises to those we have seen in (red) or (green), was possible in case of colour ascriptions. So, given what person we are talking about, the standard of tallness varies and so vary the truth and falsity of our tallness ascriptions ("S is tall" is true of a $140 \mathrm{~cm}$ seven year boy and it is false about a professional basketball player). Inferential potential of " $\mathrm{S}$ is tall" is broad and it always involves collateral premises (that specify certain class that a person belongs to) in inferences from situations to sentences.

One might wonder if it is not the case that we have multiple concepts of tallness that are essentially different; for instance, there might be a "general" concept of tallness and "relative" concept of tallness. I think that there is no "general" concept of tallness; even if one is $220 \mathrm{~cm}$ tall, we cannot say that he or she is "just tall", because, for instance, $220 \mathrm{~cm}$ is not much for a Wookiee (from "Star Wars") or $\mathrm{Na}$ 'Vi (from "Avatar"). I am reluctant to say that there are multiple concepts of tallness. Any inference from situation to sentence "S is tall" always contains ascription of certain feature-tallness. If it is the case that a certain object has that feature in high intensity, then we are allowed to say that it is tall. The point where the abovementioned high intensity of tallness starts, is relative to the class that the object we are talking about belongs to. The quantity of centimetres is the essential element of any inference from situation to sentence " $\mathrm{S}$ is tall"; the collateral premises specifying reference class vary from case to case. Summarising, "S is tall" has one inferential potential, but multiple inferential significances; each reference class has a separate inferential significance.

\section{Ordering a steak}

Suppose that John is sitting at the table in the restaurant and says to the waiter: "Bring me a steak with fried potatoes". According to Searle, there are multiple background assumptions that contribute to the meaning of the sentence "Bring me a steak with fried potatoes", for example that John expects the steak to be served on the plate and not pushed into his pocket or put onto his head; that the steak would not be encased in concrete. If John is a regular guest in the restaurant and has some familiarity with the waiter, there might be an expectation that the steak will have a specific degree of roasting (1992: 180) etc.

What is the meaning of the sentence "Bring me a steak with fried potatoes"? It seems that it is a request, and the request would be fulfilled if and only if the two following conditions are jointly met: (1) the steak is brought to John; this is the steak 
that was at some distance from John and was transported to his direct proximity (and it does not matter if it was brought by a waiter, a drone or a specially trained monkey) and (2) the object that is brought to John actually is a steak (the same applies to fried potatoes). And that's it. There are no multiple inferential significances like "steak-served-on-the-plate" or "steak-not-immersed-in-an-aquarium" etc. It is unintuitive to claim that being served on the plate or not being immersed in an aquarium is part of the meaning of "steak". If there is any expectation that the steak should not be encased in concrete or immersed in an aquarium etc., it comes not from the meaning of "Bring me a steak" itself but rather form the meaning of "This is a restaurant". This seems to be the case because John is sitting at the restaurant, and clearly we are allowed to infer from " $x$ is a restaurant" that "One can get something edible in $\mathrm{x}$ ".

So, radical contextualist claim that there are numberless things that contribute to the meaning of "Bring me a steak", but inferentialist can easily disagree. It seems that there is one inferential potential of a sentence "Bring me a steak" and we can say that the steak was brought each time a steak was brought. It does not matter how well the steak is roasted or is it served with green pepper or some type of sauce etc. If one requests for steak, one's request is fulfilled whenever one gets a steak. The degree of roasting, flavour and similar things does not constitute the meaning of a sentence "Bring me a steak". Let me remind you that normative inferentialism is an essentially social theory of meaning. The inferential potential of a sentence is determined by socially instantiated rules for inferences (cf. Peregrin 2014; Drobňák 2017) and the knowledge possessed by a waiter that a client prefers a specific degree of roasting of his steak does not constitute the inferential potential of a sentence, because it is a matter of knowledge of two people, not a matter of social rules for inferences.

\section{E. Cut the sun!}

Another example considered by Searle is an order "Cut the sun!" (1992: chapter 8). He seems to claim that such an order is incomprehensive without the knowledge of many background assumptions. One would not know what to do when hearing such an utterance. Additionally, one may claim that declarative like "Bill cut the sun" does not seem to have truth-conditions without supplementing that sentence with multiple background assumptions.

One may argue that "Cut the sun!" and "S cut the sun" lack meaning at all. We cannot cut the sun using scissors or knife. Such an utterance does not make sense, so the situation with "Cut the sun!" may be seen as analogous to the case when a person brings a bizarre-shaped piece of wood to the chess championships and tries to play a match with that additional and unknown item that is not specified in the chess rulebook. For a piece of wood to be a chess figure, it has to be subject to rules governing its use. In the absence of these rules, a piece of wood is not a chess figure; it is a merely physical object and a normative inferentialist may be inclined claim that "Bill cut the sun" or "Cut the sun!" are just sound waves; thus, one cannot make a genuine move in a language game by uttering them. 
Of course, one might imagine a situation where "S cut the sun" would make sense; for instance during a party where there is a sun-shaped cake, but in such a scenario, "S cut the sun" would be an ellipse of "S cut the sun-shaped cake into pieces". If it is the case, then such an example would be useless for a contextualist since they generally aim at showing that when the context of non-elliptical, nonvague utterance changes, then its content changes too. So, ellipses are not normally treated as genuine challenges that contextualists make against semantic minimalism or literalism.

However, there is one more possibility. We can understand, uncontroversially, the word "cut" as roughly synonymous with "reduce". If that is the case then "Cut the sun!" or "S cut the sun" can be contextualised in such a way that we can understand it as non-elliptical in certain circumstances. For instance, one can imagine someone saying, "Cut the sun!" in a theatre production (where the sun is artificial and can be turned off or dimmed). In another context, it might be a request to close a shade or curtain, where the sun itself isn't being cut, but the sunlight. It this situation "Cut the sun!" (or "S cut the sun") is basically equivalent to "Turn down/reduce the light!" (as "Kennedy cut the income taxes" is equivalent to "Kennedy reduced the income taxes"). I must remind the reader that normative inferentialism is an essentially social theory. An expression has meaning if and only if there are rules concerning inferences involving such expressions, and these rules need to be resonating thorough the society (these rules manifest in attitudes of competent language speakers). So, the ultimate test is if speakers react to "S cut the sun" as they react to "Kennedy cut the income taxes". If they do, then one must admit that "S cut the sun" has clear and well-established meaning (if they react differently, then probably we can classify "S cut the sun" as creative use of language, some sort of linguistic innovation etc.). So, we have inferential potential that contains only one inferential significance, no process of delimitation to occur.

\section{F. Smith weighs 80 kilos}

Consider the sentence "Smith weighs 80 kilos". According to contextualists, it expresses different things in different circumstances (Travis 1985; Searle 1978; check Cappelen and Lepore 2005 chapter 1 for critical discussion). For example, it may be the case that the bathroom scale indicates 80 kilos when Smith is standing on it in the morning just in his underwear or it might be the case that Smith is a soldier and weighs 80 kilos when wearing his winter uniform, heavy backpack and holding a rifle gun. In the first scenario, "Smith weighs 80 kilos" might be an appreciation of his success in reducing weight and in the second scenario, it might be the case that he is too heavy to get on the board of certain loaded helicopter.

Probably I should start with investigating the inferential potential of "Smith weighs 80 kilos". Since Smith's weight is an empirical matter, the inferences from situations to sentences are crucial. Normally, it is correct to infer that Smith weighs 80 kilos when he is standing on the scale and it indicates 80 kilos. However, the standards of precisions of weight ascriptions are little slack. One may wear underwear or not, one may (or not) has eaten a breakfast, but these things do 
not seem to matter a lot. Consider the issue of official weighting of boxers before the fight: the issues of eating a meal before the weighting or wearing underwear are not so important. If a boxer wore a backpack or a coat, we would have said that there is something wrong with the weighting process and it is not correct to infer that he weighs 80 kilos. Hence, sentences of the form " $\mathrm{S}$ weighs $\mathrm{x}$ " are concerned with ascriptions of bodyweight and they are little slack (and this is not unusual situation; check colour ascriptions and try to answer where the precise boundary between red and pink is). Since we inferred from a certain specific situation that Smith weighs 80 kilos, we are allowed to make inference that, for example, he is lighter than an elephant and he may take a specific dose of a certain drug.

What is going on when somebody utters "Smith weighs 80 kilos" in the case of Smith wearing a uniform, heavy backpack and carrying a rifle gun? One cannot simply make correct inference from the situation where Smith is standing on the scale with all this additional items to the sentence "Smith weighs 80 kilos". That utterance can be treated as correct only if it is an ellipse of "The joint weight of Smith, his uniform, his backpack and his rifle is 80 kilos". So, there is one inferential potential and one inferential significance of the sentence "Smith weighs 80 kilos". Scenarios that are supposed to prove that there is some shift in meaning of "Smith weighs 80 kilos", depending on whether he is wearing a backpack etc., are in fact ellipses or incorrect inferences from situations to sentences.

\section{G. Ordering some coffee}

Suppose that Mary is sitting at a bistro or restaurant and she utters to the waiter: "I would like some coffee". A few minutes later, a waiter brings Mary one kilogram bag filled with coffee beans or a 10-L bucket filled with a beverage. Contextualists (cf. Travis 1985; Searle 1978) may claim that the content of such utterance is determined by background assumptions; for example, the fact that Mary is sitting at the bistro makes it the case that she requested a cup of coffee. If she were in some market or shop, her request would mean that she wants a bag of coffee beans.

Once again we have a situation of a request made to the waiter. It seems that such a request is fulfilled when two following conditions are jointly met: (1) the coffee was brought to Mary, this is the coffee that was in some distance from Mary and was transported to her direct proximity (and, once again, it does not matter if it was brought by a waiter, a drone or a specially trained monkey) and (2) the object that was brought to Mary actually is coffee. However, there seem to be one important difference between the coffee and steak scenario. To see that, let's sketch the inferential potential of the sentence "This is coffee". First, it seems that one is allowed to infer that "This is coffee" from both types of situations: when one encounters coffee beans and when one encounters the drink. The inferential potential of "This is coffee" seems to allow us to infer form "This is liquid", "This is not cocoa", "This is not juice", "This contains caffeine", "This is brewed" and "This is coffee" that "This is a coffee beverage" and also "One 
can drink that" (inference from sentences to actions). Additionally, the inferential potential of "This is coffee" allows us to infer from "This contains caffeine", "This is a berry", "This is not green pea" and "This is coffee" that "This is coffee bean", and then "One can use that to brew a beverage" (inference from sentences to actions). Summarising, the inferential potential of "This is coffee" consists of two parts, which are separate inferential significances: "coffee beverage" and "coffee bean". One can find a graphical illustration of the simplified inferential potential of the sentence "This is coffee" below:

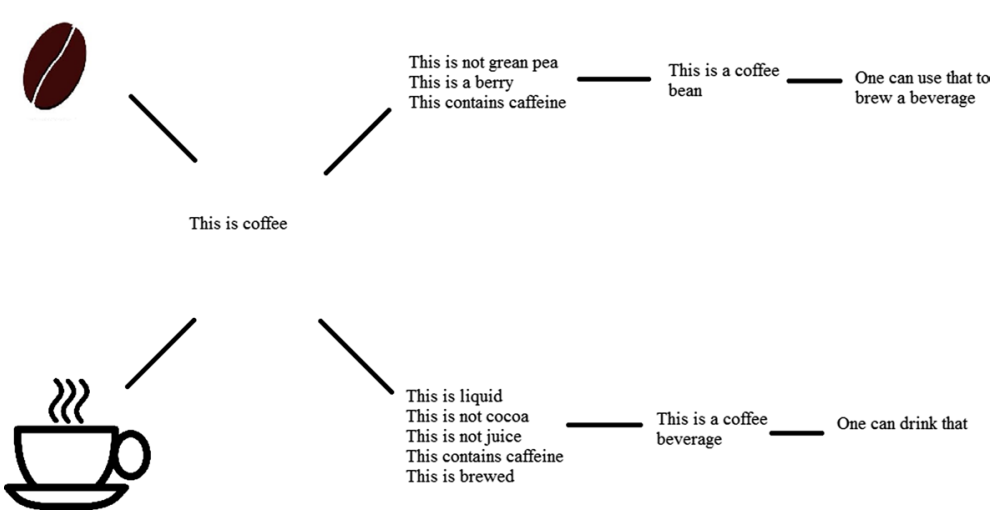

Keep in mind that the picture in the bottom left corner of the schema is just a symbol: it is not a cup, but a drink in general. So, it appears that it is irrelevant whether the waiter brought Mary a cup or a bucket of coffee. The inferential significance in the lower part of the schema seems to not differentiate the modes of serving a coffee. One is allowed to infer "This is coffee" when one encounters a cup, a glass, a $1-\mathrm{L}$ jar, a $10-\mathrm{L}$ bucket or $100-\mathrm{L}$ barrel; the only thing that is important is if the beverage is actually coffee, which may be with milk or sugar, cold or hot etc. Simply speaking, beverage is beverage, and each time Mary gets a beverage, one cannot deny that she was given coffee. Her satisfaction is, however, a different question. It is exactly the same thing as it was in the case of degree of roasting of a steak; it does not matter.

How can an inferentialist account for the situation when Mary is sitting at the bistro or restaurant and the waiter brings her a bag filled with coffee beans? Once again, personal satisfaction of Mary is, in this case, irrelevant, but what matters is the rule-determined pattern of correct inferences. The inferential potential of the sentence "This is coffee" is broad enough to include both beverage and beans. We make the process of delimitation of relevant inferential significance from inferential potential, given the context of utterance. Apparently, it is correct to infer from "This is a bistro" that "One can order a coffee beverage there", but not "One can buy coffee beans there". The fact that Mary is at the bistro or restaurant modulates (delimits) the meaning of the sentence "I would like some coffee" to its content "I would like a coffee beverage". When a waiter brings her a bag of beans, he or she does something wrong, and not because of Mary's subjective lack of satisfaction, 
but because the waiter incorrectly modulates the meaning of the sentence "I would like some coffee". One may argue that it is possible that at some places, one can both buy a coffee beverage and coffee beans, so there is no mistake in the waiter's behaviour. That is not correct. Normally, one can get a beverage at a bistro, cafe or restaurant, and that is the constitutive part of inferential significance of "This is a coffee beverage". One can infer from "This is a bistro/cafe/restaurant" that "One can buy a coffee beverage there" and not "One can buy coffee beans there". However, all inferences are cancellable, so one cannot infer from "This is a bistro/cafe/ restaurant" that "One can buy coffee beans there", unless in that specific bistro/cafe/ restaurant, they are selling coffee beans. If that would be the case, Mary's utterance "I would like some coffee" is not specific enough to make any delimitation of inferential potential of that utterance; therefore, the only proper behaviour on the waiter's part is to ask what Mary has on her mind: beverage or beans.

Finally, I would like to answer the issue of why the cases concerning steak and coffee, that look similar, are resolved in a slightly different way, in a sense that sitting at the restaurant/bistro is somehow important in the coffee scenario but not in the steak scenario. There is a crucial difference: "I would like some coffee" has multiple inferential significances ("beverage" and "beans"), whereas "Bring me a steak" has only one inferential significance. That makes a difference because according to the account presented in this paper contextual modulation is a process of delimitation (specification, narrowing) from multiple inferential significances to the specific one, given that certain collateral premises are true. When we have multiple inferential significances, the fact that Mary is sitting at the bistro/restaurant acts as a trigger of specific inferential significance (the beverage one), and when we have just one inferential significance (as in the steak scenario), there is no room for a process of delimitation to occur.

\section{Inferentialism and Contextual Modulation}

Normative inferentialism is a theory that identifies sentence meaning with the role conferred to that sentence by rules governing three types of inferential transitions (from situations to sentences, from sentences to sentences and from sentences to actions). According to such a theory, sentence meaning (inferential potential) can be understood as broad, but invariant. Content of utterance (inferential significance) is just a part of that broad sentence meaning. Importantly, the theory is essentially social: rules for inferences of all types need to be socially instantiated. Without such rules, there is no meaning.

When empirical language is considered, normative inferentialism is able to produce interesting results in accounting for prominent scenarios presented by contextualists as a challenge for semantic minimalism/literalism. Sentences in question can be seen by an inferentialist as:

1. having one inferential potential and multiple inferential significances (scenarios A, B, C and G) 
2. having one inferential potential and one inferential significance (scenarios D and $\mathrm{F}$, perhaps scenario E)

3. having no meaning at all, i.e. not being real sentences (perhaps scenario E)

From inferentialist perspective contextualists' arguments of the type I are flawed and arguments of the type III are valid to some extent: we need to involve some context from the outset. However, normative inferentialist has good resources to refute radical contextualist's scenarios as clearly wrong or senseless. Arguments of the type II do not pose any thread for inferentialist because he or she does not believe that truth-conditions determine linguistic meaning or play essential role in communication.

One may argue that I am a little too harsh for contextualists when I rule out certain sentences as having no meaning at all. Perhaps it is true, however even if it is true, it does not undermine my account. This is the case because contextualist arguments, to be considered as valid, need to be concerned with "standard sentences"; this is not vague, non-elliptical, non-metaphorical and not some sort of linguistic innovation or poetry etc. On the inferentialist account, if there are no rules concerning inferences, there is no meaning. However, it might be the case that there are no rules resonating thorough the society and the expression is not just a sound wave: it might be linguistic innovation, poetry ${ }^{7}$ etc., but such linguistic phenomena are not useful for contextualists to make their point.

As one can see, inferentialism has certain advantages: it addresses contextualist arguments in a simple fashion that requires only one procedure of delimitation; due to its social character, it is able to rule out some scenarios sketched by contextualists as clearly senseless. Normative inferentialism might be a non-standard approach to linguistic meaning, but it has big potential.

\section{Conclusions}

If one wonders how normative inferentialism relates to the main positions in the debate concerning the context-dependence of linguistic expressions, then one must be aware that it does not fit neatly into any category. It shares with literalism and minimalism the view that there are few linguistic expressions that change meaning (or extension) when context changes ("I" or "tomorrow" are obvious candidates). However, if one wanted to treat inferential potential as an equivalent of minimalist "minimal content", one would be mistaken because inferential potential is clearly not what is common to all inferential significances; rather, it is a set of all inferential significances the sentence in question has. Inferentialists clearly disagree with contextualists that context-dependence is an omnipresent phenomenon and that

\footnotetext{
7 Probably famous Recanati's example "Sandwich with ham left without paying" fits well into this category. There are no rules for inferences resonating thorough the society concerning such a sentence, so when we hear it, we recognize it in a flash as not a "standard sentence", but something else (ellipse, implicature, linguistic innovation etc.).
} 
semantic "what is said" is heavily influenced by multiple pragmatic processes. Inferentialists can claim that we can specify context-invariant meaning; however, such a meaning is broad. Moreover, we do not need multiple pragmatic processes to determine the content of the expression; one process of contextual modulation (narrowing, that is, selecting the proper inferential significance from inferential potential) is just enough. The reason we do not need multiple pragmatic processes is that some of those pragmatic influences contextualists speak about are included in the meaning of the sentence "from the beginning" (as we have seen in the "Fido is a dog" example), and some others (like the degree on roasting of a steak) do not contribute to the sentence-meaning.

Radical contextualists may claim that there is no such thing as inferential potential, only inferential significance. To some extent inferentialists can agree with that. After all, inferentialism is a use-theory of meaning, and such theories understand linguistic meaning as reification of use, not as some sort of entity (like a proposition). Inferentialism clearly prioritizes content over meaning. However, inferential potential (sentence-meaning) plays an important theoretical role within the theory presented in this paper. We start the process of contextual modulation form an inferential potential (set of inferential significances) and select proper inferential significance, given the circumstances (context). Without the inferential potential, there can be no process of contextual narrowing of that potential to relevant significance. Hence, it seems that if we get rid of inferential potential and claim that there is only inferential significance we are left with a theory with limited explanatory power. However, even such a weak theory clearly can rule out many contextualist claims as incorrect (for instance, that there are numberless extralinguistic factors that contribute to the content of the utterance; inferentialists can still appeal to rules resonating thorough the society to refute such claims as we have seen in the steak scenario). Summarising, normative inferentialism is an alternative view to traditional referential semantics, and as such it is very hard to decidedly classify it as belonging to any part of the contextualism vs minimalism debate; however, it seems to have resources to make a contribution to that debate.

Acknowledgements I would like to thank two anonymous referees for this journal for their constructive reports that helped me improve my paper. I am grateful to Matej Drobňák, Tadeusz Ciecierski, Piotr Makowski, Olga Poller, Joanna Guzowska and Tomasz Zyglewicz for their comments on the earlier version of this paper. Ideas expressed in this article were presented at the Center for Language, Logic and Cognition seminar in November 2019, during my EPSA fellowship in Turin, Italy.

Open Access This article is licensed under a Creative Commons Attribution 4.0 International License, which permits use, sharing, adaptation, distribution and reproduction in any medium or format, as long as you give appropriate credit to the original author(s) and the source, provide a link to the Creative Commons licence, and indicate if changes were made. The images or other third party material in this article are included in the article's Creative Commons licence, unless indicated otherwise in a credit line to the material. If material is not included in the article's Creative Commons licence and your intended use is not permitted by statutory regulation or exceeds the permitted use, you will need to obtain permission directly from the copyright holder. To view a copy of this licence, visit http://creativecommons.org/licen ses/by/4.0/. 


\section{References}

Ajdukiewicz, K. (1934). Sprache und Sinn. Erkenntnis, 4(1), 100-138.

Bach, K. (1994). Conversational impliciture. Mind and Language, 9, 124-162.

Bach, K. (2001). You don't say? Synthese, 128, 15-44.

Belnap, N. D. (1962). Tonk, plonk and plink. Analysis, 22, 130-134.

Bezuidenhout, A. (2002). Truth-conditional pragmatics. Philosophical Perspectives, 16, 105-134.

Boghossian, P. A. (1993). Does an inferential role semantics rest upon a mistake? In E. Villanueva (Ed.), Philosophical issues 3 (pp. 73-88). Atascadero: Ridgeview Press.

Boghossian, P. A. (1994). Inferential role semantics and the analytic/synthetic distinction. Philosophical Studies, 73, 109-122.

Boghossian, P. A. (2003). Blind reasoning. The Aristotelian Society Supplementary, 77, 225-248.

Boghossian, P. A. (2012). Inferentialism and the epistemology of logic: Reflections on Casalegno and Williamson. Dialectica, 66, 221-236.

Borg, E. (2004). Minimal semantics. Oxford: Oxford University Press.

Borg, E. (2012). Pursuing meaning. Oxford: Oxford University Press.

Brandom, R. (1994). Making it explicit: Reasoning, representing, and discursive commitment. Cambridge, MA: Harvard University Press.

Brandom, R. (2000). Articulating reasons: An introduction to inferentialism. Cambridge, MA: Harvard University Press.

Brandom, R. (2007). Inferentialism and some of its challenges. Philosophy and Phenomenological Research, 74(3), 651-676.

Cappelen, H., \& Lepore, E. (2005). Insensitive semantics. A defense of semantic minimalism and speech act pluralism. Oxford: Wiley-Blackwell.

Carston, R. (2002). Thoughts and utterances: The pragmatics of explicit communication. Oxford: Blackwell.

Cozzo, C. (1994). Meaning and argument: A theory of meaning centred on immediate argumental role. Stockholm: Almqvist \& Wiksell International.

Drobňák, M. (2017). Meaning-constitutive inferences. Organon F, 24(1), 85-104.

Drobňák, M. (2020). Inferentialism on meaning, content, and context. ActaAnalytica, 35, 35-50. https://doi. org/10.1007/s12136-019-00394-0

Dummett, M. (1973). Frege: Philosophy of Language. London: Duckworth.

Felscher, W. (2002). Dialogues as a foundation for intuitionistic logic. In D. M. Gabbay \& F. Guenthner (Eds.), Handbook of philosophical logic (pp. 115-145). Dordrecht: Springer. https://doi. org/10.1007/978-94-017-0458-8_2.

Fouqueré, CH. \& Quatrini, M. (2013). Argumentation and inference: a unified approach. In The Baltic international yearbook of cognition, logic and communication volume 8: Games, game theory and game semantics (pp. 1-41). New Paririe Press.

Francez, N. (2015). 2015. Proof theoretical semantics: College Publication.

Grice, P. (1957). Meaning. Philosophical Review, 66(3), 377-388.

Kaplan, D. (1989). Demonstratives. In J. Almog, J. Perry, \& H. Wettstein (Eds.), Themes from Kaplan (pp. 481-563). New York: Oxford University Press.

Lewis, D. (1970). General semantics. Synthese, 22, 18-67.

Peregrin, J. (2006). Meaning as inferential role? Erkenntnis, 78, 1-35.

Peregrin, J. (2014). Inferentialism. Why rules matter. London: Palgrave Macmillan.

Peregrin, J. (2018). Isinferentialism circular? Analysis, 78, 450-454.

Prior, A. (1960). The runabout inference ticket. Analysis, 21, 38-39.

Recanati, F. (2004). Literal meaning. Cambridge: Cambridge University Press.

Recanati, F. (2010). Truth-conditional pragmatics. Oxford: Oxford University Press.

Searle, J. (1978). Literal meaning. Erkenntnis, 13, 207-224.

Searle, J. (1992). The rediscovery of the mind. Cambridge, MA: MIT Press.

Sperber, D., \& Wilson, D. (1986). Relevance: Communication and cognition. Oxford: Blackwell.

Stanley, J. (2007). Language in context. Oxford: Oxford University Press.

Travis, Ch. (1985). On what is strictly speaking true. Canadian Journal of Philosophy, 15(2), 187-229.

Travis, Ch. (1997). Pragmatics. In B. Hale \& C. Wright (Eds.), A companion to the philosophy of language (pp. 87-107). Oxford: Blackwell Publishers.

Warren, J. (2015). Talking with tonkers. Philosophers'Imprint 15. 
Wittgenstein, L. (1967). Philosophical investigations (G. E. M. Anscombe, R. Rhees, \& G. H. von Wright Eds., E. Anscombe, trans., 3rd ed.). Oxford: Blackwell.

Wittgenstein, L. (1969). The blue and brown books. Oxford: Blackwell.

Zangwill, N. (2015). Logic as metaphysics. Journal of Philosophy, 112, 517-550.

Publisher's Note Springer Nature remains neutral with regard to jurisdictional claims in published maps and institutional affiliations. 